\title{
The general practitioner
}

\author{
T. L. VENABLES \\ M.B., M.R.C.P., M.R.C.G.P. \\ University of Nottingham
}

\begin{abstract}
Summary
Despite the instruction he receives in medical school, the general practitioner prescribes mainly by trade names. He receives much information, for example advertising and visits from representatives, in which drugs are identified by trade names. Of greatest importance, these at present provide the most convenient and satisfactory method of ensuring that the patient receives a product which will be consistently effective.
\end{abstract}

A RECENT editorial in the Journal of the Royal College of General Practitioners (1973) reminds us that William Osler observed that one of the differences between man and animals is man's desire to take drugs. With easier access to the General Practitioner and the explosion of scientific advance in the field of clinical pharmacology with its attendant publicity via the mass media, this difference is very much more marked now than it was even in Osler's day. The doctor himself feels an almost innate desire to prescribe, and Parish noted in 1971 that 'It is easier to prescribe than to give advice'.

These two pressures contribute to the fact that between $60 \%$ and $70 \%$ of consultations in general practice result in a prescription being given.

Having reached the stage where the decision to give a prescription has been made by the General Practitioner, the conscious question of whether this should be written in trade name or approved name form arises only infrequently. We are creatures of habit and a number of factors have been involved in the evolution of the method of writing a prescription for a particular drug.

\section{Undergraduate learning}

During our undergraduate training most of us will have been implored by our teachers to use approved names for drugs at all times, and to eschew brand names at all costs. I wonder what the reaction would have been if in our final MB examination papers we had suggested Imperacin or Terramycin as a suitable antibiotic for the treatment of bronchitis, instead of oxytetracycline.

\section{Postgraduate learning}

During vocational training, General Practitioners become more aware of brand names as by this time they find themselves reading the journals as well as the text books, and who can fail to be influenced by the mass of advertising that many journals now $\infty$ necessarily contain. Most General Practitioners read $\mathrm{O}$ something out of most issues of Update which is The Postgraduate Journal of General Practice. In the ${ }_{\mathbb{D}}^{\top}$ 1971 volume of Update Plus, out of 966 pages there $\frac{\text { 을 }}{}$ were 388 full pages of pharmaceutical advertising and in one monthly issue there were only three double pages with no full page advertising materigi $\overrightarrow{0}$ at all. The brand names of drugs are thrust at us, a the proper names are usually only to be found small print at the bottom of the page.

Having become principals in General Practice, there is less exposure to formal courses of instruction in therapeutics, and practitioners are more easily $\frac{}{\Phi}$ influenced (not always adversely) by visits from representatives of pharmaceutical companies whose brand of a particular drug is always better than that of its competitors. Reading the Prescribers' Journal or the Drug and Therapeutics Bulletin may make one at least aware of the approved name of the newer compound being used, but the total exposure to this name is only just above the subliminal level.

\section{Ease of writing}

Most brand names of drugs are shorter, more 을 easily associated with the condition or symptom they $\frac{7}{2}$ treat, and more euphonious than the approved name. In a busy surgery, when the doctor is working $N_{O}$ at full pressure, these can become very important $N$ factors. Table 1 is taken from a recent paper on $\mathcal{N}$ drug usage in general practice (Berkeley and $\omega$ Richardson, 1973). It shows the frequency of prescription of the most commonly used drugs among ${ }^{\circ}$ twelve General Practitioners in Scotland. Table $2 \stackrel{\Phi}{\Phi}$ shows the preparations most commonly prescribed when a single-handed doctor looked at his prescribing habits over a period of 4 separate months $\frac{\mathbb{D}}{\mathbb{D}}$

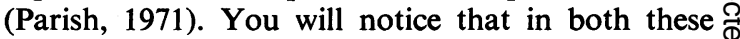


TABLE 1

\begin{tabular}{lc}
\hline \multicolumn{1}{c}{ Drug } & Prescriptions \\
\hline Phenoxymethyl-penicillin & 362 \\
Paracetamol & 263 \\
Oxytetracycline & 246 \\
Ampicillin & 171 \\
'Benylin' & 156 \\
Diazepam & 131 \\
'Betnovate' & 129 \\
'Navidrex' & 125 \\
Acetylsalicylic acid & 111 \\
Aluminium hydroxide & 110 \\
Nitrazepam & 107 \\
'Actifed' & 102 \\
\hline
\end{tabular}

TABLE 2

\begin{tabular}{llc}
\hline \multicolumn{1}{c}{ Drug } & & Prescriptions \\
\hline Penicillin & v caps & 101 \\
Digoxin & tabs & 74 \\
'Tuinal' & caps & 62 \\
'Librium' & caps & 59 \\
Pholcodine & linct. & 49 \\
Phenobarbitone & tabs. & 45 \\
'Raudixin' & tabs & 40 \\
Tetracycline & caps & 30 \\
'Codis' & tabs & 26 \\
Penicillin & G susp. & 26 \\
Ferrous sulphate & tabs & 26 \\
'Largactil' & tabs & 26 \\
Phenylbutazone & tabs & 24 \\
'Choledyl' & tabs & 23 \\
\hline
\end{tabular}

tables there is a mixture of brand names and approved names. Some are combined preparations but others seem to be randomly allocated a brand name or approved name with no underlying rationale.

\section{Expense}

In many cases the cost to the National Health Service of drugs prescribed by approved name is considerably less than if brand names are used. General Practitioners are reminded at frequent intervals by the Department of Health of this fact, by regular circulars in the form of histograms. These can sometimes have a very chastening effect.

Those General Practitioners who dispense drugs are probably more aware of the relative cost than their non-dispensing colleagues, and the fact that they dispense may also influence their decision on whether to use brand names or not. I wonder if we may be sometimes unconsciously persuaded to write the brand name if our profit on dispensing is going to be greater. I hope not, but I suspect that it may sometimes happen.
It is sometimes necessary to take into account the cost of drugs to the patient, particularly to those people who may require a number of different compounds. If the doctor is aware that they are not eligible for free prescriptions and that they are financially vulnerable he may feel it desirable to use combined preparations where feasible. In almost every case these are prescribed by the brand name. He may also use combined preparations where he feels the patient's reliability in taking drugs is suspect.

\section{Effectiveness}

Our prime consideration in prescribing should be whether or not the drug is going to be effective, reliable and consistent in its action. Most concern in this area is directed at drugs which are to be used over the long term in conditions such as diabetes mellitus, epilepsy, hypertension, arthritis and cardiovascular disease. Many of the newer and effective preparations which have been introduced are, or will be shortly, available from sources different from those with which we have always associated them. What we really want to know is whether the methyldopa which we have been prescribing with consistent effectiveness for the last 5 years for our 45-year-old hypertensive coal-miner will continue to give consistent control when it comes from another source. The fact that each tablet will contain $250 \mathrm{mg}$ of the active ingredient is of little significance if the particle size changes, or its rate of absorption is altered because the machine which manufactures the tablet is pressing those particles more firmly together, resulting either in a rise of the patient's blood pressure to uncontrolled levels, or excessive lowering leading to hypotensive episodes. Oral anti-diabetic agents are even more important in this respect, particularly those which can cause hypoglycaemic coma. We have all felt the effects of 'the digoxin affair', and unless action is taken now, a repeat performance in another field must eventually come, perhaps with disastrous results.

The study of general practice prescribing mentioned above (Berkeley and Richardson, 1973) covered 26 randomly selected days over a 1-year period, and the twelve General Practitioners involved prescribed a total of 401 different drugs; the average for each doctor being 116. Wilson (1971) in an analysis of his own practice found that he used 148 different compounds in 1 year and he was confident that he used only a small number of well tried preparations. Patterson (1972) found that he used 403 different preparations when he audited his prescribing habits retrospectively in 4 different months over a 3-year period.

It is, therefore, apparent that the General Practitioner has to carry a lot of prescribing information 
about with him. It is unreasonable to expect him to remember several names for the same drug, let alone the possible differences between varying preparations of the same compound. For the time being, the safest course would seem to be to use the cheapest, most effective brand name until the regulations on the manufacture of drugs are tightened up to include the method of manufacture, particle size, solubility and bio-availability for every drug marketed. We shall then not be confronted with the potential hazard which now faces us every time we write a prescription.

\section{References}

Berkeley, J.S. \& Richardson, I.M. (1973) Drug usage inc general practice. Journal of the Royal College of General Practitioners, 23, 155.

Journal of the Royal College of General Practitioners (1973) Editorial: Prescribing in general practice. Journal of the Royal College of General Practitioners, 23, 151.

PARISH, P.A. (1971) The prescribing of psychotrophic drugs in general practice. Journal of the Royal College of General Practitioners, 21, Supplement No. 4.

Patterson, J.S. (1972) How many drugs do I use? Journals of the Royal College of General Practitioners, 22, 191.

WiLson, D.J. (1971) Domiciliary prescribing. Journal of the Royal College of General Practitioners, 21, 558. 